\title{
First Case of Alice in Wonderland-like Seizures in a Mother and her Daughter: A New Sign for a Hereditary Origin?
}

\author{
Stefan Bittmann*, Anne Weissenstein, Elisabeth Luchter, Elena Moschüring Alieva and Gloria \\ Villalon \\ Department of Pediatrics, Ped Mind Institute (PMI), Germany
}

*Corresponding author: Stefan Bittmann, Department of Pediatrics, Ped Mind Institute (PMI), Germany.

To Cite This Article: : Stefan Bittmann, First Case of Alice in Wonderland-like Seizures in a Mother and her Daughter: A New Sign for a Hereditary Origin?. Am J Biomed Sci \& Res. 2019 - 6(4). AJBSR.MS.ID.001047. DOI: 10.34297/AJBSR.2019.06.001047.

Received: 制 November 05, 2019; Published: 眥 December 02, 2019

\begin{abstract}
Alice in Wonderland Syndrome (AIWS) was named after the description of Lewis Carroll in his novel. In1955, John Todd, a psychiatrist described this entity for the first time. Todd described it as "Alice's Adventures in Wonderland" by Lewis Carroll. The author Carroll suffered from severe migraine attacks. Alice in Wonderland Syndrome is a disorienting condition of seizures affecting the visual perception. AIWS is a neurological form of seizures influencing the brain, thereby causing a disturbed perception. Patients describe visual, auditory and tactile hallucinations and disturbed perceptions. The causes for AIWS are still not known exactly. Cases of migraine, brain tumors, depression episodes, epilepsy, delirium, psychoactive drugs, ischemic stroke, EBV, mycoplasma and malaria infections are correlating with AIWS like seizures. Neuroimaging studies reveal disturbance of brain regions including the temporoparietal junction, the temporal lobe and the occipital lobe as typical localization of the visual pathway. A hereditary form of AIWS-like seizures in 2 familiars (mother and daughter) were not described before and could be a sign for an underlying genetic origin. Moreover, in the daughter, AIWS seizures were only present in relaxed and tired situations and lying position.
\end{abstract}

Keywords: Alice in wonderland child; Hereditary; Genetics; Familial

\section{Case Report - Familial History}

\section{Short history of the 26 years-old daughter}

Visual perceptions began early in kinder garden only in situations when lying down and very tired with closed eyes, never in standing or awake situations. After a while pictures of different parts of the body were present. In these visual perceptions, the other parts of the body were not possible to see because one part of the body imposing so big. Visual perceptions occur most often in relaxed lying conditions. She most often realizes the thumb as much too big. The other body parts were realized as big length and the body form very narrow. It did not happen very often, but these perceptions did not make anxious or nervous in the moment of realization. She also described disturbed perception of time. The daughter has a history of THC drug abuse, opiates and alcohol, and ADHS. These visual impressions were never present after excessive parties with drug abuse. Visual perceptions were found in extreme tired situations. There was no history of migraine but of bipolar-2 disorder personality and generalized anxiety disorder (GAD).

\section{Short history of the 47 years-old mother}

Age of the mother 47. The mother has borderline personality disorder and acute panic disorder. The mother has an extreme form of migraine. AIWS seizures occurred in summer 2014 without occurrence of migraine. The seizures occur, when she is full of fear inducing panic attacks as a result of the visual perceptions she realized. In these moments, she cannot divide reality from seizure perception. Most often she realized her hands too big, like the thumb in the daughter, which show the same localization in the upper extremity. She, also like her daughter, describe disturbed perception of time.

\section{Short history of the father}

The father died as the daughter was 13 years old and had a history of drug abuse and schizoaffective disorder.

\section{Discussion}

The British psychiatrist John Todd described the state of micro- and macrosomatognosy in children, with changing the 
visual perception of own`s body image with induction of bizarre body illusions [1-3]. This entity with disturbed visual perception was described as Alice in Wonderland Syndrome. Todd published his first experience in 1955 and defined its literary name in his publication. Caro Lippman was one of the first authors, who described, in 1952, the syndrome for the first time. Illusionary body perceptions can trigger fear in the patients, sometimes many years in early childhood [4-6]. AIWS is most often found in children, but also found in adults and elder patients. The normal development can be influenced in the family and at school [7-10]. AIWS has been described in various publications in connection with many different infectious diseases such as malaria, zicavirus, varicellainduced optical neuromyelitis, Lyme disease, H1N1 flu infection, and mononucleosis [11-14].

Moreover, is obvious that all these different diseases do not play a role in finding the true origin of Alice in Wonderland syndrome [15-20]. A recent publication pointed out the correlation of visual impairment in perception with anti-N-methyl-D-aspartate receptor (NMDAR) encephalitis [21]. Differential diagnosis includes Charles Bonnet Syndrome [22]. AIWS like seizures correlate with migraine [5-8], epilepsy, acute disseminated encephalomyelitis [9], abuse with LSD or montelukast [10]. AIWS like seizures can therefore occur in drug related settings. In our case, the daughter never had any AIWS-like seizure after intake of drugs in parties. Furthermore, seizures were present after ventricular shunt surgery in hydrocephalus operation and was described in patients after brain tumor resection like glioblastoma. Another fact is, curiously, that earlier publications describe the aspect of AIWS correlating with sexual abuse. In these publications, two older women aged 57 and 61 years describe their horrifying experiences with sexual abuse with the father and report years after their experience independently of AIWS after many years [17-20]. These sensitive and curious experience from internet shed light on aspects of sexual abuse by describing the entity many years after the experience of both older women analyzing their experience as children [17-20].

The hallmark of AIWS could be migraine, like in our case in the mother. The daughter had no migraine and described the seizures more intensively and curious. Individuals with AIWS-like seizures lose sense of time, like in our case in the mother and the daughter. Time seems to pass too fast. Extreme visual hallucinations were found in a few patients with AIWS; they can visualize things that do not exist and can also realize a disturbed impression of situations and events. Visual perception is distorted, as are acoustic and tactile perception. Verbal auditory misperceptions were also described $[15,16]$.

The facts and the origin about AIWS are still unclear; not many pediatricians know about the disease. Many case reports were published in literature, but no study about a group of patients still exist for research of this curious entity. AIWS has no effective treatment and no clear algorithms for AIWS treatment do exist. Chronic cases of AIWS in children are quite extremely rare. Our familial case report shed light on a possible hereditary genetic aspect. Mother and daughter have similar visual AIWS-like perceptions. Underlying diseases were present, but only the mother had migraine attacks.

In this familial case report, a genetic origin must be supposed. Next generation sequencing and mutation analysis and other genetic analysis could help in this way. The contact was made by email from the US to Germany. The daughter contacted the author from Columbus, Ohio (USA) and described the experience the mother and her daughter made in the past with exact descriptions of their visual perceptions in the moments of seizure. Very interesting new aspects are in conclusion the possible hereditary aspect, the presence of a seizure only in lying relaxed condition with closed eyes and that the visual perceptions were not fear triggering in the daughter, but only in the mother. Disturbance of time perception was found in both, in the daughter and the mother, so time perception seems to be a typical part of AIWS-like seizures. This familial case shed light on genetic origin, and this should be underpinned by more similar cases.

\section{References}

1. Gaul C, Kraya T, Holle D, Benkel Herrenbrück I, Schara U, et al. (2011) Migraine variants and unusual types of migraine in childhood. Schmerz 25(2): 148-156.

2. Lanska JR, Lanska DJ (2013) Alice in Wonderland Syndrome: Somesthetic vs visual perceptual disturbance. Neurology 80(13): 1262-1264.

3. Losada Del Pozo R, Cantarín Extremera V, García Peñas JJ, Duat Rodríguez A, López Marín L, et al. (2011) Characteristics and evolution of patients with Alice in Wonderland syndrome. Rev Neurol 53(11): 641-648.

4. Pacheva IH, Ivanov IS (2013) Migraine variants Occurrence in pediatric neurology practice. Clin Neurol Neurosurg 115(9): 1775-1783.

5. George D, Bernard P (2013) Complex hallucinations and panic attacks in a 13-year-old with migraines: The Alice in Wonderland syndrome. Innov Clin Neurosci 10(1): 30-32.

6. Pacheva I, Ivanov I (2013) Acute confusional migraine: Is it a distinct form of migraine? Int J Clin Pract 67(3): 250-256.

7. Li N, Jia FY, Du L, Jiang HY, Li HH, et al. (2012) Alice-in-Wonderland syndrome as first presentation of migraine in a child. Zhongguo Dang Dai Er Ke Za Zhi 14(11): 881-882.

8. Bayen E, Cleret de Langavant L, Fénelon G (2012) The Alice in Wonderland syndrome: An unusual aura in migraine. Rev Neurol (Paris) 168(5): 457-459.

9. Coven I, Horasanli B, Sönmez E, Coban G, Dener S (2013) The Alice in Wonderland syndrome: An unusual in acute disseminated encephalomyelitis. Am J Emerg Med 31: 638.e1-3.

10. Bernal Vañó E, López Andrés N (2013) A case of Alice-in-Wonderland syndrome probably associated with the use of montelukast. An Pediatr (Barc) 78(2): 127-128.

11. Kuo SC, Yeh YW, Chen CY, Weng JP, Tzeng NS (2012) Possible association between Alice in Wonderland syndrome and influenza A infection. J Neuropsychiatry Clin Neurosci 24(3): E7-E8.

12. Binalsheikh IM, Griesemer D, Wang S, Alvarez Altalef R (2012) Lyme neuroborreliosis presenting as Alice in Wonderland syndrome. Pediatr Neurol 46(3): 185-186. 
13. Nakaya H, Yamamoto T, Takano M, Yamamoto K, Hujikawa Y, et al. (2011) Alice in Wonderland syndrome caused by the 2009 pandemic H1N1 influenza A virus. Pediatr Infect Dis J 30(8): 725-726.

14. Piessens P, Indesteege F, Lemkens P (2011) Alice in Wonderland syndrome and upper airway obstruction in infectious mononucleosis. B-ENT 7(1): 51-54

15. Blom JD, Looijestijn J, Goekoop R, Diederen KM, Rijkaart AM, et al (2011) Treatment of Alice in Wonderland syndrome and verbal auditory hallucinations using repetitive transcranial magnetic stimulation: A case report with fMRI findings. Psychopathology 44(5): 337-344.

16. Slotema CW, Blom JD, Looijestijn J, Goekoop R, Diederen KM, et al (2011) Treatment of Alice in Wonderland syndrome and verbal auditory hallucinations using repetitive transcranial magnetic stimulation: A case report with fMRI findings. Psychopathology 44(5): 337-344.

17. Bittmann S (2018) The clue to the unknown origin of Alice in Wonderland in Children? Pediatr Res Child Health 2(1): 001.
18. Bittmann S, Luchter E, Villalon G (2018) Does sexual abuse play a causative role in Alice in Wonderland Syndrome in Childhood? A help screaming from internet. J Perina Clin Pediatr pp. 104.

19. Bittmann S (2018) Abuse in children: Indicator of failure in relationship? Adv Pediatr Res 5: 16

20. Bittmann S (2018) Alice in Wonderland Syndrome in childhood: Abuse is the root? J Pediatr Dis Volume 2.

21. Funayama M, Mizushima J, Takata T, Korrekt A, Mimura M (2018) Altered perception might be a symptom of anti-N-methyl-D-aspartate receptor (NMDAR) encephalitis. Neurocase 24(5-6): 255-258.

22. Anand S (2019) Alice in Wonderland syndrome and Charles Bonnet syndrome: Similar but not so similar! Aust NZJ Psychiatry 53(6): 585. 